\title{
Sexual Gender-Based Violence in Greek Refugees Camp
}

\author{
Khairunnisa Nadhifa ${ }^{1}$, Adhi Cabya Fabadayna ${ }^{2}$ \\ Universitas Brawijaya
}

\begin{abstract}
In 2015 the European Migrant Crisis pushed Europe to a new dimension of issues and problems. With the mass of people migrating into the region, Greece became one of the front-line countries to face the crisis by hosting the country's high refugee population. Due to their incapability to adjust and respond according to the needs and situation of the crisis, other issues rise within Greek settlements among refugees themselves where violence came into existence. Sexual and Gender-Based Violence (SGBV) appears in the refugee population that targeted women refugees living in the Greek camps. To know exactly why the causes of SGBV to happen in the first place against women refugees can be known through the effort of the Heise Model by Lori Michau to seek the root problems of the causes that drive the reason SGBV to exist within risky situations such as refugee camps. Through this Heise Model, the author seeks the causes of why SGBV happened in Greek refugee camps in 2015-2018 in covering four levels of societal, community, interpersonal, and individual.
\end{abstract}

Keywords: Greece, SGBV, Greek Refugee Camps, Heise Model

\section{INTRODUCTION}

In the scope of international relations, the concept of violence can be implemented in various forms. Violence can be explained through feminist perspectives. It can analyze the forms of violence in interpersonal space such as violence against women or use traditional perspectives in prioritizing the violence between actors, for instance, conflicts between groups or states (Thomas, 2011). According to Johan Galtung in his journal titled Violence, Peace, and Peace Research, he stated that 'peace is where violence is absent' indicating that violence itself is a form that threatens the placement of security therefore appearing in between issues constructed in society (Galtung, 1969). Galtung places three types of violence based on his research. The first is direct violence, which correspond to acts that threatens life itself or belittle basic human needs; second is structural violence, which is formed in systematically where individuals or groups were cut access for opportunities and services; thirdly, cultural violence which is formed by social norms and beliefs throughout the community that results in inequality, unfairness, and injustice widely accepted as common norms (Galtung, 1969). In broader sense, violence is the act of intended physical force or power through threatening against another individual, group or community, where it will result in the end of injury, death, psychological harm, maldevelopment, or deprivation (WHO, 2002). This definition relates to how violence conveys to the intentional use of 'power' as a tool in order to assert the means to hurt or threaten another.

Victims of SGBV falls to all subjects whether they are men, women and children. However, it is commonly happening towards women and girls in risky environment that do not exactly maintain their well-being of safety. SGBV usually prone to focus on violence against women and girls (VAWG) because they fall most into this violence category. Even though SGBV on VAWG is considered a global pandemic that affects 1 in 3 women in their lifetime, the numbers of violence are difficult to track as this issue is considered difficult to assess globally (The World Bank, 2019). We can know that through the scope of the problem 
WHO based report conducts that 35\% women worldwide experienced physical or sexual assault from their perpetrators, globally around $38 \%$ of women received assault committed by intimate partners and around 200 million women went through Female Genital Mutilation (FGM) (The World Bank, 2019). The numbers proved that this issue is clearly a widely dangerous case that risks the security of all women and girls throughout the world based on the characteristic of SGBV that were contributed by the backgrounds of social, cultural, and economic aspects in both developed and developing countries. Overall, by 2018, there were about 135 millions of people around the world including both genders in need of assistance to fight against SGBV (GBV AOR Strategy, 2020). The perpetrators of SGBV can be conducted by anyone whether it is individuals from their communities, from refugee communities, humanitarian actors, and authorities who abuses their power. Additionally, social norms and gender roles along with displacement can be the trigger to cause conflict within local areas (UNHCR, 2019).

According to UN Women in the midst of the mass movement there is a notable amount of $42 \%$ of women and children in the refugee population which makes the amount of men around 58\% (UN Women, 2015). The primary reasons of why the refugees chose to move to Europe especially to Western European countries is because they wished to seek better chance of living in developed countries in European countries. However, in some cases they had to seek in European countries because the capabilities of seeking refuge in Middle Eastern countries, such as Jordan, Lebanon, and Turkey do not accommodate to their wellbeing fully (Telegraph, 2015). To which we bring to the situation of the European migrant crisis that escalated in 2015 where Greece becomes one of the most strategical country for refugees to enter Europe via sea departure from Middle Eastern countries and North African countries. To enter further into European countries especially towards Western European countries, the refugees have to take the risk of transit from countries hosting refugees which are Greece, Turkey, and Italy. Afterwards they continue their tracks through Balkan routes such as Slovenia, Bulgaria, and Hungary (Dockery, 2017). One of the routes that migrants entered through dangerous and illegal track is through Aegean Sea in Lesbos island where it has become the opening door towards mass refugees from Syria, Iraq, and Afghanistan (Tempo, 2018). Which is why at this point Greece experienced incredible traffic with the mass amount of refugees entering and seeking asylum in said country, turning the country to its maximum point of hosting refugees from the mass movement up to 66,969 people by 2018 (Asylum Information Database n.d.).

The victims of SGBV in this case were mostly female as the women refugees in Greek refugee camps were common to face more SGBV compared to the male refugees. As the report concluded that $80 \%$ of survivors from refugee population on SGBV were women compared to men, 20\%, by 2017 UNCHR 12 report (Monica Costa Riba, 2018). The writer's main purpose of this research is to seek why the violence regarding sexual and gender-based aspects happen in the respective study case and to provide possible prevention of SGBV as reference by the writer in the recommendation section that may be included in the future as reference to policy contribution towards the case with the title of Sexual and Gender Based Violence Against Women in Greek Refugee Camps In 2015- 2018. With this intention, the writer will mainly seek to explain the background causes of the SGBV and why it happened in the Greek refugee camps in analysis and later to provide the prevention references through recommendation section on how to fight and end the violence in said place. This work will consist of qualitative and explanative type. This explanative method will be used to explain the study case of sexual and gender-based violence against women refugees in Greek camps in 2015-2018. 


\section{ANALYTICAL FRAMEWORK}

\section{Sexual and Gender Based Violence as Concept}

While Sexual violence, gender-based violence and violence against women are words that are common use in the same notion, they are all defined to how violence is form based on the threat of individual or groups of individuals based on the gender norms and sex roles that are implemented. In the end they all produce to the form of violence common through physical, sexual, and psychological harm that involves the dominant power dynamics of masculinity and inferior femineity in power and control (UNHCR, 2003). Understanding SGBV as a concept is to acknowledge the term through the definitions. The word sex correlates with the biological distinction of male and female. However, these distinctions are restricted to the reproductive functions (UNHCR, 2003) On the other hand, gender correlates with the social distinctions placed on men and women and they are constructed based on the factors of age, religion, nationality, ethnic, and social background (UNHCR, 2003). There is a power correlation with the distinctions to how they interact with one another that corresponds to the changes and format in the social, political, and cultural spheres. From the previous statement, we can understand that the distinctions affiliate with one another whether it is for men, women, or any other gender - they are all defining the very notion of gender identity where one is formed through behavior influenced by their roles, responsibilities, and their statuses (UNHCR, 2003).

In deeper explanation to the understanding of power correlation, approaching first to what it contributes and influences to the imbalance of power between genders. Imbalance of power derives from the fact there are norms, and most commonly, negative norms applied in the ideas and values implemented within a group or community that exists within the social framework. In social norms, it goes way beneath the understanding how ideas and values contribute to the discourse of an individual of how one should behave and shape their role based on their thoughts. Which could be contributed from how male and female acts for example, men and boys majoring in masculine and dominating roles such as physical hard-work, being leaders, becoming bosses and earning high top positions whilst women and girls majoring in feminine and submissive roles in less physical work than men, becoming housewives and taking positions in lesser places of any duties. SGBV itself is may include the form of sexual and physical assault however it is important to remember that SGBV roots aren't necessary from the drive of sexual intentions but in the showcase of domineering power and control from one subject to another. Therefore, SGBV may appear in common public context however it is deeply rooted from the understanding of individuals, groups, community, and society on the attitudes that excuse violence to happen within their environment.

SGBV formally known in common to apply to women only in broader aspect but in definition context, violence can result to happen to both genders - whether they are male or female. SGBV towards men also came into context as males can be both victims or perpetrators. Male victims of SGBV falls under the experience of domestic abuse, sexual violence, stalking, honor-based violence which involves forced marriage as well as prostitution (UK Government, 2019). However, in many cases, male falls upon the category of being perpetrators of violence in SGBV case due to the toxic norms upholding based on the grounds of masculinity in their dominant society. For men living in society that are restricted and upholding negative norms in implementing bad traits towards men in the society it can contribute to how one embraces these norms. And whether these norms are accepted or rejected by an individual, it can contribute typically to how form of SGBV may be produced. Upon to the other gender, SGBV commonly relates to violence against women and girls since it was due to the global acknowledgement of how women became the victims 
of SGBV. There is approximation that $35 \%$ of women worldwide has experienced violence and around 70\% have experienced form of Intimate Partner Violence (IPV) (UN Women n.d.). This comes to the understanding that SGBV against women has become a global pandemic and one of the most rising issues in international scale to discuss in preventing and eradicating it. Into understanding why women become the common victims that falls into this violence because of the norms across cultural and religious context of how women roles played feminine and submissive part in many societies around the world that placed them as lesser or second gender in the society making them placed in weaker and lesser power in position in their lives, which opens to risks to any forms of violence that may be able to slip through.

To support the following model, this research will be using Judith Butler's approach on Gender in contributing the existence of violence. Butler's explanation towards gender is quite complex in defining what comes to the definitions in the approach towards gender. She claims that it is difficult to comprehend violence into the platform of gender because it is often being underestimated and at the same it is heavily controlled (Butler, 2007) With this claim, the highlighted points of violence can be seen from gender by how it was shaped by the existence of sexualities and how concepts contribute towards social and cultural norms that are interchangeably manifesting to the outcome of violence (Çınar, n.d.).

When applied to support Model Heise, it can be seen through that individual, interpersonal, and community levels that from the construction of social and cultural origins which shaped the norms affects greatly as their own indicators within the variables available. In Model Heise it is important to understand how violence occurred through the approach of the causes first to recognize the complex relation between individual, interpersonal, community, and societal factors (Michau, 2007). Therefore, using Butler's approach on Performativity theory helps us to understand Heise Model inspiration origins of the formation of the construction framework in variables and indicators applied for the analysis through understanding how norms performed and influenced through acts of subjects is said to be related to their gender identity heavily attributes in the levels of individual, interpersonal, and societal levels.

\section{Heise's Model}

To support the following model, this research will be using Judith Butler's approach on Gender in contributing the existence of violence. Butler's explanation towards gender is quite complex in defining what comes to the definitions in the approach towards gender. She claims that it is difficult to comprehend violence into the platform of gender because it is often being underestimated and at the same it is heavily controlled (Butler, 2007) With this claim, the highlighted points of violence can be seen from gender by how it was shaped by the existence of sexualities and how concepts contribute towards social and cultural norms that are interchangeably manifesting to the outcome of violence (Çınar, n.d.).

When applied to support Model Heise, it can be seen through that individual, interpersonal, and community levels that from the construction of social and cultural origins which shaped the norms affects greatly as their own indicators within the variables available. In Model Heise it is important to understand how violence occurred through the approach of the causes first to recognize the complex relation between individual, interpersonal, community, and societal factors (Michau, 2007). Therefore, using Butler's approach on Performativity theory helps us to understand Heise Model inspiration origins of the formation of the construction framework in variables and indicators applied for the analysis through understanding how norms performed and influenced through acts of subjects is said to be related to their gender identity heavily attributes in the levels of individual, interpersonal, and societal levels. 
In this research, the writer will use Heise Model that was developed by Lori Michau, Jessica Horn, Amy Bank, Mallika Dutt, and Cathy Zimmerman, as instrumental tool to analyze the case used in this research study. The model that the writer will be using is from the reference of paper series titled Prevention of violence against women and girls: lessons from practice (Michau et al. 2015). The main understanding of this model is how to transform gender-power inequalities through a focus of framework towards the importance of systems and programs that overlook the socio-ecological forms such as social interactions, institutional, culture, context of individual and politics. Therefore, the writer will further try to explain why violence happen based on the factors the influenced in the framework. Heise Model can be applied as a tool of instrumental analysis to assess the violence that influenced through gendered factors in all aspects in social, institutional, culture, and politics which is formed in 4 different levels: individual, interpersonal, community, and societal (Michau et al. 2015) This model is one of the model that can be used to use as identifying and preventive approach to seek how violence can occur and the solutions through preventions of violence program based on the five main principles (Michau et al. 2015) The first one is analysis and actions to prevent violence across socio-ecological aspect (individual, interpersonal, community, and societal). The second is the framework of intervention based on the interactions from the influence of gender-power analysis in interpersonal aspect. Third is the model theory that is used as instrumental tool for analysis. Fourth is the investment inside the maintenance of multisector intervention. Fifth is the aspirations to continue the programs through activism in order to prevent VAWG in other areas.

Figure 1: Transformation of power across the socio-ecological model

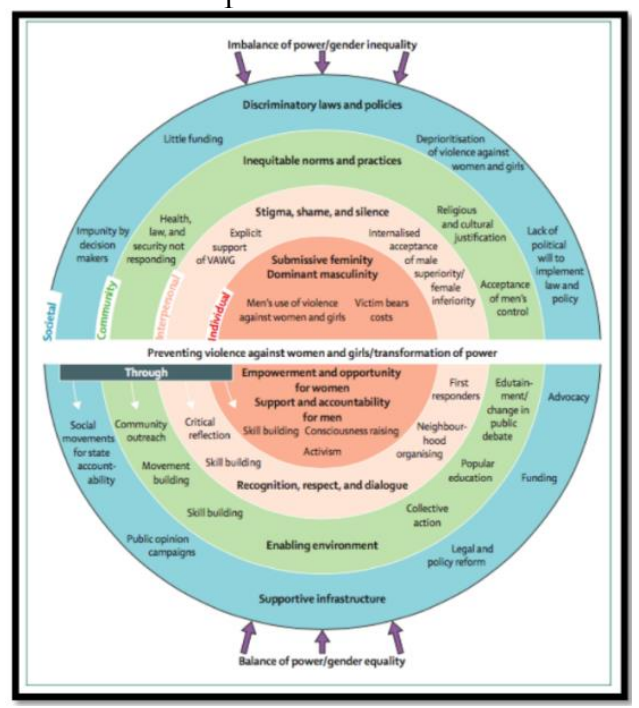

Source: Lori Michau, Jessica Horn, Amy Bank, Nallika Dutt, Cathy Zimmerman, Prevention of violence against women and girls: lessons from practice

This model tells us how the form of violence exists within the aspect of socioecological format and how the levels shown in the diagram influenced from one to another (Michau et al. 2015). From the model that shows the main mechanism cause of violence it starts from the form of imbalance of power/gender inequality that appears right outside the room of societal level. It is believed that the imbalance of power/gender inequality influences directly throughout the levels within the transformation of power across the ecological model based on how deeply rooted the power and values societies implemented upon men and women. As such the risks towards gender often found in forms 
of discrimination and inequality on race, class, ethnicity, caste, religion, disability, HIV status, migration status, sexual orientation, and gender identity (Michau et al. 2015). Moving on, from societal level it is influencing systematically towards the discriminatory laws and policies (Michau et al. 2015). The said aspects explained how the construction created by the society form and shape the creation of policies, law, and infrastructure service. This level will be influencing towards the following level which is community in which this aspect covers the inequitable norms and practices (Michau et al. 2015).

\section{RESULT AND DISCUSSION}

The timeline of European Migrant Crisis surfaced in 2015, however the issue of many refugees crossing borders beyond their countries started earlier way before that. Refugees, who we know by the definition as people who flee from their home countries in order to avoid persecution due to their race, religion, nationality, political standing or members of distinct group, are at risk state of seeking safety and security when they decided to leave their origins (HIAS n.d.). However, specifically for European Migrant. Crisis escalated in 2015 drives from various triggers that set the mass movement of people crossing borders to Europe.

The main trigger escalation of the mass migrant movement in Europe by 2015 was due to the ongoing civil war that was happening in Syria (Kingsley 2019). It is clear that by 2015, the people with the largest number who entered Europe through was mostly Syrians who escaped from their country due to civil war that was unlikely to cease any time soon, the people believing that there was no other choice than to escape from the horrors in their home country and seek better place of living elsewhere which is why the decided to risk their lives on their journey towards Europe. Another reason why they chose to go to Europe was because the inadequate conditions for refugees in the neighboring countries of Middle East as it was known that the legal entrance to Arab countries was difficult and in the countries like Turkey, Lebanon, and Jordan did not give best facilities for refugee who are seeking security and access to basic needs such as education which seems to be one of the things that are falling out for the refugee children living beyond their national borders (Kingsley 2019). The other reasons for refugees other than Syrians who flee from civil wars were mostly because they had similar issues like Syria where in their original countries also faced conflicts that increased in drastic measures such as Afghanistan and Iran, Eritrea faces strict dictatorship similar to North Korean-regime, Kosovo went through high poverty, and other refugees from other countries faced similar unsafe living conditions or faced persecutions for their political or religious beliefs (Taub 2015).

For refugees moving towards Europe, the data showcased that the main destinations for them to seek better place was in Western European country such as Germany which open its arms in welcoming more than 467,000 people entering the country in 2015, however there were also other countries affected by the mass movement of people seeking refuge in their countries even though they were not the first destination of plans for instance Hungary, Sweden, and Austria that were affected the most for asylum applicants (BBC 2016b; Kingsley 2019). Regardless of their destination, the journey that took them from their original places towards Europe took various methods of transportation, however it is known due to the massive surge of numbers of people migrating - therefore illegal tracks were used by the refugees in order to get to the place quicker whilst it may risk their lives on the way throughout their journey.

According to OECD there were about three pathways of channels for the refugees to take their journeys in going to Europe by 2015. The Eastern Mediterranean and Western Balkan route is one of the frequent pathways used of asylum seekers coming from Syria, Iraq, 
and Afghanistan followed by Pakistani, African migrant groups, and others who wished to depart from the Western Balkan region (OECD 2015). The Western Balkan routes include passing countries of Macedonia, Serbia, Hungary, and Croatia before making it across to Western Europe (Frontex n.d.). Though not many came directly from their home countries but they used routes from Turkey where they take their first transit before continuing their journey through dangerous sea travels with boats then finally moving on to the Balkan routes once they reached European soil in order to reach Western European countries. However, in the Western Balkan route were where many illegal crossings usually occur due to the country borders covered with spike fences to prevent illegal crossings. The next one is Central Mediterranean route which cross through the sea mostly from Libya to Italy by boats (Frontex n.d.; OECD 2015). And the third one is Western Mediterranean route, also used with dangerous sea travels with boats, where the routes were from Northern African countries and reaching to Spain (Frontex n.d.; OECD 2015).

Nonetheless of their entry, the journey was deathly and risky for the asylum seekers to reach their way to Europe. In result many deaths included in the travels of the asylum seekers, most commonly through the sea routes. As claimed by reports, the overview of people arriving to Europe from 2015 until 2018, whether by land and sea, arriving in Italy, Cyprus, Greece, and Spain can be summarized as stated in the following data. For the arrivals there were 1,032,408 in 2015 with the highest number and then decreasing by the following years in 2016 with 373,652 people, 2017 with 185,139 people, and lastly in 2018 with 141,472 people (UNHCR n.d.). However, it also cost the lives of people with 3,771 people dead and missing in 2015, by 2016 there were increased number with 5,096, however decreased once more in the following years by 2017 with 3,139 people and in 2018 with 2,277 people (OECD 2015).

Based on the data of Operational Portals related to the total number of people arriving in Europe in 2015-2018, the number is increasing massively every year. Following the massive numbers of people entering Europe and applying for asylum, it is no lie that even the European countries found themselves in a pinched situation with the overflowing number of people coming. Following the responses by EU, which represents the large institution of Europe, along with non-state members involved as well, were given various responses towards handling the migrant crisis from 2015 until 2018. At this point, due to the heightened number of refugees entering causing the newest strike of mass movement of migrants makes a history for Europe that responded in various statements according to this issue through policies. First and foremost, to the involved countries represented through institution which is European Union, pointed many decisions on to adapting to this case.

According to Concilium-Europe, there are about 26 Policies and agreements as the responses on migration crisis in Europe by European Union in 2015-2018 (European Council n.d.). Based on the implementations and actions, the responses towards of EU for the crisis resulted various implementations, cooperation, and programs in order to seek the solution and lessen the flow of the problem which they were concerned in certain aspects which was clear to distribute among the European nations. These aspects were; strengthening the presence of rescuers at seas, to fight illegal transnational activities involved during the sea routes, stemming migration flow, presenting cooperation on relocation of number of refugees, providing better shelters and protection for refugees, and fortifying new implementations and regulations on asylum status for refugees and their integration to host countries (European Council n.d.).

However, even with the cooperation between EU and non-member state countries could not resolve the crisis. Though the numbers of refugees to Europe shows significantly decreasing - further issues rose within the European nations even with the cooperation of 
their neighboring countries far in the South such as Turkey and Northern African countries in trying to stem the flow of migrants coming to Europe. Relocation schemes did not provide the adequate solution to resettlements in Europe, which also heightened the risk and situation of refugees remaining stuck within transit countries without being properly relocated in purposed destinations (Carina Grun n.d.). Other bold responses even with the alarming state of refugees seeking for asylum in European countries, several countries such as Poland, Hungary, and Czech Republic in refusing refugee quotas and even create barbed wire fences in order to push out the migrants seeking for asylum, creating political and humanitarian unrest along with other European members in administrating their noncompliance with their legal responsibility (BBC News 2017). Even through the efforts and responsibilities of the actors involved in the migrant crisis, the issue did not resolve in ending the matter nor it results the best sufficient conditions for refugees seeking asylum in Europe as they hoped it would be. The incapability between political struggles of countries in creating strategic implementation to curb the migration issue was not solved appropriately at cost, causing more problems for the refugees themselves in imperfect conditions of shelters and survival across the continent.

\section{Greece Situation Regarding to Migrant Crisis}

Based on the report of ICF and UNHCR, the heightened number of arrivals in Greece by 2015 is notably high compared to the previous year in 2014 with 856,723 numbers approximately and decreased in the following years with 173,450 people in 2016, 29,718 people in 2017, and 16,531 people in 2018 (ICF 2018). Particularly on which areas of Greece the refugees arrive are on islands of Lesbos, Dodecanese, Samos, Chios, Crete, and Cyclades (ESI 2015). From what can be gathered, to compare the dynamics of gender arrivals from 2015 until 2018 consists within the total number of arrivals. As of 2015, there were about $20 \%$ of women and $40 \%$ of men of refugees arrivals to Greece (UNHCR 2016a). In 2016, there were about $21 \%$ of women and $42 \%$ of men of refugees arrivals(UNHCR 2016b). In 2017 , there were about $22 \%$ of women and $41 \%$ of men of refugees arrivals (UNHCR $2017 \mathrm{~b}$ ). And lastly in 2018, there were about $23 \%$ of women and $40 \%$ of men of refugees arrivals in Greece (UNHCR 2018c). It can be summarized that by 2018, the population of male refugees dominated the refugee population in Greece by $40 \%$ compared to women which only took the numbers around 20\% throughout the years between 2015 until 2018 with the total population number staying in Greece by 2018 with 71,200 people (UNHCR 2018). Although in comparison, Greek citizens' population consist of $10,724,599$ with gender comparison of men $(5,208,293)$ and women $(5,516,306)$ - the population overall in Greece becomes overcrowded with the additional numbers of refugees staying (Countryeconomy 2018).

There were around 16 documented origins of nationalities the refugees came to the islands of Greek, among them Syrians, Afghans, and Iraqis came in with the largest amount of refugees entering Greece compared to the other nations (ESI 2015). By 2018, the population were filled with $26 \%$ of Syrian Arab Republic refugees (Men with $31 \%$ and women 25\%), 26\% of Afghanistan refugees (Men with 31\% and women with 25\%), and 19\% of Iraq refugees (Men with 37\% and women with 22\%) - while the rest of the refugee population filled with Congo, Palestine and others (UNCHR 2018).

With a lot of number of people coming to Europe due to the triggers of increasing violence in their original countries, there are also other reasons why the refugees decided to choose Greece as one of the places to seek refuge in Europe. As stated previously in the background, the refugees' initiatives into moving to Greece was because they had been in Greece for a long period of time for their settlement as well, another was because they believe 
that the living condition in Greek camps were adequate enough though it, and the last one was because they had a failed attempt into migrating to another country previously in which they decided to choose Greece as their new destination to settle (Kuschminder 2018). Nevertheless, the response of refugee who arrived in Greek camps also had new plans to move outside of Greece which were because they had been in Greek camps for a long duration of stay, they had experienced inadequate living conditions that couldn't help them to get through due to the poor facilities, they had their asylum process fail because most were often rejected $(12 \%)$ or delayed $(13 \%)$ for asylum application in Greece, and finally most wished to find new better living opportunities beyond Greek nation (Kuschminder 2018).

Greece was more or less, burdened with responsibility to welcome and host the refugees coming to their shores. Nonetheless, as a member state of the EU and part to the convention in 1951 that Greece signed to the Geneva Convention of 1951 and the protocol in 1967 which means they have to abide to the basis of asylum-law principle of nonrefoulement where they had to accommodate asylum seekers who fit in to the criteria (Library of Congress n.d.). They are obligated to follow the regulations in which they have to make possible access to equal and coherent asylum process, and to make sure that preparing facilities that are accessible with confinement as last accountable plan of action (Valentza 2018). By international treaties and customary law, ships owned by Greece (both state-owned and private-owned) are also obligated to help any vessels in need of emergency (UNHCR 2018). Even so, Greece also established center service for asylum seekers for management in 2013 where it ensures international protection and create functional system for border management and the returns (Library of Congress n.d.; UNCHR 2018).

Regarding to the crisis, the response of the both the government and the local population has been reasonable as they come to the terms that Greece had to deal with this problem effectively. As of the current period of year, Prime Minister Alexis Tsipras and his opposition leader Kryiakos Mitsotakis even stands on the same page of concern over the humanitarian aspect of the refugee crisis happening in Greece which they stated that new management and framework towards policies needed support and cooperation in global scale (Kalantzakos 2017). In political scale, the Greeks expressed concerns in dealing with the refugee crisis especially with how the right-wing party presented fear of placing refugees as burden to the country in terms of social and political aspect, however the population and the government solidify in cooperation in order to deal with the crisis effectively. Despite the effort of dealing as host to the incomers, the issue of racism, discrimination, and xenophobia still appear in the midst of the locals however many solidarity acts have moved people of local communities in Greece to provide help such as shelter, food and water.

In overall view of responses to the crisis, Greece has several outcomes in the migration policies according from the past until this recent crisis. Before 2015, Greek's response to challenges of migration were inconsistent as there were the lack of effective integration policy with long-term plan. It was only a new beginning in 2011 when the Greek Parliament finally established new law 3907/2011 to implement an separate office for Asylum and First Reception Services (Dimitris Skleparis 2017). Afterwards, they weren't able to reinforce better external regulation for migration security. On the rising crisis in 2015, the Greek government finally took the right turn in improving the laws regarding towards migration for both placed on mainland and the islands, especially with the help of the EUTurkey statement to aid their process in improving their policies onto the year 2016 (Dimitris Skleparis 2017). A new law implemented by 2016 which is 4375/2016 stating an developed asylum system to be placed on Greek islands and other border areas in order to better control and regulate the displaced people in the country who are protected by international rights (Dimitris Skleparis 2017). 
Since Greece also rely on international help from donations from the UN, EU and other organizations - however not all donations flow directly to the government to allocate the findings functionally (Howden, Daniel and Fotiadis 2019). The EU has plans to create long-term fund of 561 million Euros however it was only been distributed 153 million Euros to Greece (Leape 2018). It was due to the fact that there was lack of report on the spending of the fund, which brings to the attention that Greece was unable to distribute the funds to cease the issue evenly. Which brings to another fact that Greece was still underwhelming in controlling the situation at their best hand and unfortunately didn't manage the resources correctly among the refugee settling.

Based on the data of Greek Migration Ministry, camps in Greece of Lesbos, Samos, Chios are overcrowded and under most pressure. The camps have low capacities and overloaded people. Regardless, those who stays in camps with poor facilitations finds themselves in risk of meeting other dangers such as lack of healthcare, education, services to legal- aid, mental health and psychological support even turning into resulting new form of threat appeared within the refugee population which is violence, especially sexual and gender based violence (Dimitris Skleparis 2017).

\section{Situation for Women in Greek Refugee Camps}

Before we move on, we must understand the Greek aspect and framework regarding to SGBV in their own country to further able to compare the differences between the citizens of Greeks and the refugees who were foreigners on Greek country. Greece has a population of 10,724,499 people by 2018, with gender comparison of men $(5,208,293)$ and women $(5,516,306)$ (Countryeconomy 2018). It is known that Greece is rich in their history and culture, however the form of dominant masculine society especially in their general norms on ideas based on gender is quite masculine therefore prone to lean on patriarchy society. The victims that falls commonly upon SGBV cases in Greece were mostly women as according to data; there were approximation of 283 victims of human trafficking happened during period of 2010 - 2012 and 234 reports of rape and attempted rape in 2013 (EIGE 2016). So how often do they acknowledge or recognize SGBV as well as mentioning any prevention towards it. Through legal definitions, Greece has several forms that includes the law included in SGBV format in order to be able to understand through legal aspect for addressing the issue within the country. IPV which is included in domestic violence in the Articles 6,7,8, and 9 of act and Articles 299 and 311 of Criminal Code (European Institute for Gender Equality 2013). Following the Criminal Code, Article 336 on Rape from physical violence or threat, Sexual assault in Criminal Code, Articles 337 and 338, Sexual harassment in act 3896 of 2010 (Countryeconomy 2018).

There efforts through policies to addressing this issues; which were National action plan specific to violence against women in 2004 in addressing trafficking cases by implementing framework to act against the practice, in 2004-2008 as well as in in 2007-2013, implied policy on incorporation of violence against women in national plan/strategy (UN Women n.d.). Preventions were also included in addressing to the public through raising awareness and education. Judging by the information above, we can conclude that the issue of SGBV in Greece is quite outdated as this issue has not been raised to awareness as first priorities of problem by the government due to the lack of implementation and strategies to address and prevent SGBV in Greece itself.

It was difficult to track and monitor the whole cases of violence that happened against women refugees in the Greek camps, especially with the overcrowded population of refugees staying in Greek islands and in the mainland. However, from what we can tell from the available sources. Though there are lack of male victims, they were mostly reported as 
perpetrators from the sources available, while it may lean towards gender biased, it cannot be helped regarding to the risk of the situation of many women as victims compared to men. As the major population in the refugee community has Syria, Afghanistan, and Iraq in the population - we can draw some figures from data observed on which groups were targeted in SGBV cases that Syrians, 39\%, and Iraqis, 16\% by report (UNHCR 2017).

According to UNHCR in 2017 of refugees staying in the Aegean islands, there were about 622 reported accounts of sexual violence in which $28 \%$ of them happened after arriving in Greek shores (Council of Europe 2018). Another reported cases of SGBV reported to UNCHR in 2016 - 2017 informed that about 35\% of the cases happened in mainland whereas 65\% happened on the islands specifically located in the RICs in Lesbos and Samos (UNHCR 2017). It was also in these particular areas that the report claimed that the place was filled of shared tents between women and unrelated men. Nonetheless, it is informed that the numbers of violence reported are known to be less than what happened in reality as the reported data did not provide actual identical evidence however with the given information, we are able to draw the information regarding to SGBV that happened against women in Greek camps considered highly dangerous for these women to face in their settlements in Greek lands.

With the situation of refugees living in Greece, it is known that there is harsh reality to face the truth of the settlement. The situation for refugees in Greece were proved that they were inadequate for living and housing, not only that as other basic needs for daily survival seemed also sparse to be shared among the numbers of refugees. Firstly, the right to adequate living in which separated by the two regions which is on the Aegean Islands and the mainland. In the Aegean Islands reported that the refugees lived in containers and large tents which housed 125 people every spot together with no privacy. Whilst some others didn't get to be inside of it so they had to make their own shelter which is difficult because they cannot make it safe and stable enough for the weather (Council of Europe 2018). Insufficient water and sewage problems also occur in the islands which affects public health and the environment because the water pipes were broken (Council of Europe 2018). Lack of sanitation facilities which makes it difficult for clean and hygienic environment both for men, women, and children to access. According to Amnesty International, showers are also the place which is incredibly dangerous for women and children alike because most harassments and violence occur regularly due to the lack of safe space (Costa Riba 2018).

The mainland also shared similar problems with shelters as reception camps proved to be not appropriate for long-term accommodation as many of the overcrowded camps container and tents did not provide safe and basic needs for the refugees (Costa Riba 2018). It was noted that such basic needs were not provided fairly among the women refugees, especially to specific needs such as food and water, where women with young children and newborns finds it difficult to get food accessibly possible (Fernandes 2019). These poor circumstances along with the lack of basic needs also shared troubles with the way the accommodation in sharing between refugees caused insecurities for the women and children to live in as many shared their concern that they had to share with men who are strangers to them for women on their own or with their children, or even unaccompanied children (Amnesty International 2018).

Second is access to health care where it is reported that it was incredibly difficult to have refugees access to public health facilities because the health field proved to be under pressure as they are lacking in covering all the capacities for the services for both local population and the refugees (Council of Europe 2018). Not to forget that Greece also admitted that their services in the overcrowded reception camps were finding difficulties to meet all the needs due to the lacking number of human resources and capacities in order to 
work functionally to help all the patients. This makes it incredibly worrying for refugees who are in need of physical and mental help to the authorities especially when they have been going through traumatic experiences that required quick attention to their vulnerable situations. Thirdly, the access of legal help also proves to be difficult for the refugees. Women and children faced daily insecurity for their space and with the lack of help between the barrier of culture and language makes it difficult for them to reach out to the legal services that can help them in the situation. However, because the camps were overcrowded and there was insufficient lacking of working overlooking the whole area- it makes it quite difficult for any of the refugees to reach out for help. In other cases, this was also where the adamant harassment between women and children refugee against the service workers who also didn't treat the refugees appropriately, making it difficult for the women and children to trust the authorities, local workers such as interpreters and NGO, and even the officers because of the lack of trust and understanding between them (Amnesty International 2018).

\section{Societal}

There are some types of violence that occurred in the Greek refugee camps where it includes sexual violence, physical violence, emotional and psychological violence, harmful traditional practices, and finally socio-economic violence.

Table 1: Types of Violence towards women refugees in Greek camps in 2015-2018

\begin{tabular}{|c|c|c|}
\hline $\begin{array}{l}\text { Types of } \\
\text { Violence }\end{array}$ & Types of Acts & Description \\
\hline \multirow[t]{6}{*}{$\begin{array}{l}\text { Sexual } \\
\text { Violence }\end{array}$} & Rape and marital rape & $\begin{array}{l}\text { The violation of any part of the body of the victim } \\
\text { with an object or a sexual organ by using coercion, } \\
\text { threat, or force against a person incapable of giving } \\
\text { consent. }\end{array}$ \\
\hline & $\begin{array}{l}\text { Child sexual abuse, } \\
\text { defilement, and incest }\end{array}$ & $\begin{array}{l}\text { Violation acted against a child that is used for sexual } \\
\text { indulgence and to take advantage of } \\
\text { relations/interactions with a child. }\end{array}$ \\
\hline & Attempted rape & $\begin{array}{l}\text { Attempted use of force or threat for sexual } \\
\text { intercourse towards victim without consent. }\end{array}$ \\
\hline & Sexual abuse & $\begin{array}{l}\text { Direct threat of physical action against another by } \\
\text { improper touching, by force or coercive conditions. }\end{array}$ \\
\hline & Sexual exploitation & $\begin{array}{l}\text { The act of abusing by power or trust for sexual } \\
\text { purposes in order to exploit another. (Ex: trafficking, } \\
\text { smuggling, forced sexual acts, etc). }\end{array}$ \\
\hline & Sexual harassment & $\begin{array}{l}\text { Unwanted, repeated, and uncomfortable sexual } \\
\text { advance, attention, demand, favor from another } \\
\text { through mental or physical attack. }\end{array}$ \\
\hline \multirow[t]{2}{*}{\begin{tabular}{|l} 
Physical \\
Violence
\end{tabular}} & Physical assault & $\begin{array}{l}\text { To use with or without weapon in confronting } \\
\text { another through force of beating, burning, and killing. }\end{array}$ \\
\hline & Abuse or humiliation & $\begin{array}{l}\text { The act of using verbal abuse that insults, degrade, } \\
\text { demean, bully another in private or public space. }\end{array}$ \\
\hline
\end{tabular}




\begin{tabular}{|c|c|c|}
\hline $\begin{array}{l}\text { Emotional and } \\
\text { Psychological } \\
\text { Violence }\end{array}$ & Confinement & $\begin{array}{l}\text { To isolate victim from anyone including friends and } \\
\text { family in limited environment and to limit their } \\
\text { freedom. }\end{array}$ \\
\hline \multirow{3}{*}{$\begin{array}{l}\text { Harmful } \\
\text { Traditional } \\
\text { Practices }\end{array}$} & Early marriage & $\begin{array}{l}\text { To arrange marriage of children under the age of } \\
\text { consent. }\end{array}$ \\
\hline & Forced marriage & To arrange marriage of victims against their wishes. \\
\hline & $\begin{array}{l}\text { Denial of education } \\
\text { for girls or women }\end{array}$ & $\begin{array}{l}\text { To not let women and girls' access towards } \\
\text { educational institution, denying them for their basic } \\
\text { rights, technical, professional knowledge. }\end{array}$ \\
\hline $\begin{array}{l}\text { Socio- } \\
\text { economic } \\
\text { Violence }\end{array}$ & $\begin{array}{l}\text { Discrimination/denial } \\
\text { of opportunities }\end{array}$ & $\begin{array}{l}\text { Denial of access to education, health services, } \\
\text { employment, or rights. }\end{array}$ \\
\hline
\end{tabular}

Source: Sexual and Gender-Based Violence against Refugees, Returnees, and Internally Displaced Persons; Guidelines for Prevention and Responses.

\section{Discriminatory Laws and Policies}

First indicator is impunity by decision makers in which we will seek the factors whether this indicator proves to play a solid part of the violence happened in the study case of this research. According to the related case of SGBV against women refugees in Greek camps by 2015 - 2018, SGBV did appear as a problematic issue as the report mentioned by UNHCR stated that by 2017 there were about 622 people reported the case of violence with $28 \%$ of them occurred after they had reached the shores of Greek islands (Council of Europe 2018). Whereas it is reported in 2016 - 2017 that around 35\% of reported case happened in the mainland and 65\% happened in RICs especially on islands of Lesbos and Samos (Michau et al. 2015). Unfortunately, the sources of reported violence are difficult to track even by the officials and workers in the camps due to the insufficient lack of human resource and the capacity to do the research established based upon SGBV occurred in Greek camps specifically. However, the proved reports we understand that the number are at stake because the cases of SGBV deemed to be dangerous to the risks of the security and safety for women and girls in Greek camps especially in the aforementioned places based on the reports.

The second indicator comes to little funding and will be thoroughly examined with how this can relate to the result of SGBV in the camps. Since the condition of the refugee camps becomes the main priorities of Greek authorities, this means that they had to be able to distribute with large amount of financial situation to be able to provide and accommodate fully for the refugees staying on their land. However, the challenges come with the high numbers of refugees staying in Greek camps already placed a heavy burden on Greece in order to distribute the needs and living settlements for the refugees in the first place. By December 2018, there were about 11,683 people living in RIC settlements on the islands of Lesbos and Samos with their limit of capacity of 6,438 people. Though in other places did not necessarily overcrowd the place by December 2018, in the RIC of Chios settled with 1,014 people with the limit of 1,252 people, in Leros with 860 people with the limit of 936, and in Kos with 816 people with the limit of 762 . Nonetheless, it does not erase the fact that Greece were overwhelmed with large number of refugees settling in the amidst of the lacking facilities (Asylum in Europe n.d.).

It was addressed that Greece would receive aid from EU and other NGO supporters' in working on the situation with the refugee crisis as Greece becomes one of the strategic countries for the refugees' sail from the seas to enter Europe to through the Mediterranean route. Since Greece is also still recovering from their own financial crisis in 2015, therefore the aid of other parties was certainly welcomed to partake in order to help the crisis and the 
refugees seeking asylum in Greek soil (Zafiropoulos 2016). It was reported that the EU commission has awarded 816.4 million euros for emergency assistance by 2015 through Asylum Migration Integration Fund (AMIF) as well as Internal Security Fund (ISF) (European Comission 2019). Now the money was functioned to be used as fairly for the migration integration, border control, and refugee protection (Howden, Daniel and Fotiadis 2019). Nonetheless, with such largest amount of money donated to resolve the issue with refugee crisis in Greece, it appears to have difficulties with the financial situation.

As for refugees living costs from the aid of funding derived from cash assistance by ESTIA program managed by coordinated cooperation between Greek Government and DG ECHO funded by EU (UNHCR n.d.). This program helps to ensure access for living cost for refugees in Greece for individuals and families to meet their needs. However, even though such programs existed - due to lack of report for management, it didn't leave tracks of result information for the process of program to adapt fully to the situation for every refugee. Moving on to the third indicator of this variable which is deprioritisation of violence against women and girls in which this section will further discuss on the aspect of the respond from the Greek government in addressing the SGBV that happened right in the camps. Since it is difficult to keep track of record for SGBV that happened in Greek camps, camp workers from NGOs were able to gain insights of the cases that happened to the refugee women and were able to compile the available data into report that informed of the violent cases of women and girls experiencing dangerous events ever since they had stayed in the Greek camps as they arrived. However, it is unfortunate that it was responded negatively by the Greek government in addressing this issue as a concern of security risk for the women refugees.

The last indicator of this variable is lack of political will to implement law and policy which comes similar to the first indicator however in this sense, this indicator will focus on seeing whether regulations and policies were able to provide the safety and security of the refugees. Now for this aspect, refugees are protected by the domestic law where they take refuge and the international law that the country abides to. As Greece signed to the Geneva Convention of 1951 and 167 Protocol and also as EU member where they are obligated to protect refugees to follow the regulations of Common European Asylum System (CEAS) and to follow the Charter of Fundamental Rights of EU that concede the rights of seekers for asylum (Library of Congress n.d.). By Governmental measures, Greece also has laws concerning to Asylum seekers' reception, rights to appropriate housing, financial rights, healthcare accessibility, education for asylum seekers, and the rights to work at the labor market (Council of Europe 2018).

As for the rest of the programs held by the Greek Council for Refugees in between 2015 until 2018, proved to be solitary involved in legal aspects and raise of awareness and cater to rehabilitate to victims rather than figuring out the actual root of the problems causing SGBV to trigger in the first place upon women refugees. In addressing the findings by the writer stated above, the analysis of the aforementioned will be stated as follows. Firstly, addressing in the indicator of impunity by decision makers, the writer understands that even with the reports supporting the cases of SGBV happening in the Greek refugee camps there were still lacking acknowledgement of quick response towards SGBV which resulted the case of SGBV that happens in the refugee camps normalized because they believe that it can't be helped to address the issue directly especially with the difficult situation with the mass of people staying in the camps with little provision offered by the authorities.

Which continued on the second indicator related which is little funding. Now we know that the plan of the funding to solve the refugee crisis in Greece is not exactly small in numbers because the financial management plan was noted as one of the expensive 
allocations in history to ever be managed to help the refugee crisis which in this case is in Greece. However, it was only due to the poor management of the funding that it comes problematic for this case because it was not properly managed causing disorderly conduct of loss money and misspent money which could be provided and spent for the very basic needs of refugees which are better shelters with proper food and water, better healthcare for all medical needs whether they are physical or mental health especially towards hygiene which is the most important necessity needed, established education platform for children, better security and protection management, and integration process for the asylum seekers claims. In observing to the program of cash assistance proved not distributed throughout the population as there were lack of actual formidable reports in overseeing the progress working properly or not therefore difficult to track throughout the community to live, as well as facilities not improving overtime for healthier environment and provisions of funding not properly managed. This was also properly due to the lack of cooperation between EU and Greek government because as it was stated previously, the flow of funds were directly given straight to the NGOs to allocate instead of the Greek governments in which there were gaps of information, reports on the fund management, and the lack of trust of cooperation between Greek authorities and the NGOs which further proves disorderly in being able to provide better management if it was properly and fairly distributed to the needs of the authorities and the refugees issues to solve.

Final indicator is lack of political will to implement law and policy. Although there are signed conventions, obligated regulations of internationally legal binding rules, and the mandatory to respect the policy of receiving the claims of asylum seekers - the notion still stands that there is lack of effort by the law and policies in addressing to be able to identify and prevent the case of SGBV happening against women refugees. This brings to the understanding that if there was lack of political will of law and policy then the issue of SGBV against refugees will not be prioritized to be taken seriously and there will be weak of support by the legal framework which is supposed to be the object to aid and protect the victims of SGBV in order to have their rights fulfilled.

\section{Community}

As of for law enforcement, it proves to be quite difficult. As mentioned in the previous variable which brings familiar context that the authorities of law are not always necessarily available and ready to apprehend when cases of SGBV happened in urgency because there are lack of actual laws on protecting refugees against SGBV as many policies in concerning the refugees in Greece were more prone to focus on management, administrative, and allocation laws to cater to the population of refugees so security and safeties were not prioritized specifically especially towards SGBV (Council of Europe 2018). Therefore, making it difficult for the victims of SGBV to come out and seek help of legal bodies when they wanted to tackle the issue of SGBV with legal aid. And towards the security authorities to address the issue of SGBV were reported to not be sufficient enough to respond quick to the urgent calls to the case. Since many of the refugees came from foreign countries of different backgrounds, many did not have the ability and knowledge to be able to report their case to the security authorities because of language and basic legal understanding, where this becomes a problem since there were lack of appropriate interpreters who tackles on this case seriously. A mentioned case by the report of Amnesty International of a women stated that she even received disrespect from the interpreter when she wishes to report her situation to seek help from a sexual assault, creating gap for the victims to distrust the legal authorities more difficult in result as her report considered one of the many similar cases in the camp not being taken seriously (Amnesty International 2018). 
The second indicator of this variable to covers the aspect is religious and cultural justifications which in this case closely follow more in depth of religious and cultural values and norms that are implemented in the community based on their background and why it creates the formation of violence against women refugees in the camps. Ironically, both populations of Greek citizens and refugees were derived from the background in dominantmasculine society that were prone to have structural form of patriarchy system in their society. Most of the women refugee who came and settle in Greece came from different countries where three main countries dominates the population of the refugee community which were Syrians, Afghans, and Iraqis while the remaining refugee population came from countries of Iraq, Somalia, Bangladesh, Palestine, Iran, Congo, Eritrea, Egypt, Morocco, Algeria, and Tunisia (ESI 2015). From this information, we can pull the fact that the majority of these countries have similar cultures which are male-dominating and patriarchy and the major religion similar shared of Islamic belief for focusing in majority from Syria, Afghanistan, and Iraq.

So, if any of these norms and values be broken by the women refugees, they will face risks and consequences that can impact to their lives greatly. This understanding norm of the religious justification was also reported as one of the many cases of the refugee women who encountered to seek freedom of their abusive marriage and domestic violence occurred in the camps, with one case mentioned of a woman wishing for the possibility of divorce with her husband even though it was impossible to do it back in her original country, Afghanistan, but after gaining the knowledge that the chance was possible she also considered the situation whether she can regain her rights fully to get away from violence (Campana 2018). These norms were so deeply rooted that at times most victims didn't realize that they were victims of SGBV. Which comes to the conclusion of the difficult situation created by the justification of culture and religion that the norms and values were affecting the way the refugees' beliefs are implemented, where they were lacking in knowledge whether they can attain their rights by speaking out against their belief in keeping honor and the possibility of gaining the rights to their security by leaving an abusive relationship/marriage from their partners.

Finally, we come to the third indicator which is the acceptance of men's control and try to understand whether this aspect further affect the variable. According to the reports and news established, many believed that the women refugees accept men's control in their living situation in Greek camps even though that it connects to the form of SGBV. Whether they were shaped by cultural or religious justifications, but most importantly what were also keeping them the acceptance of the men's control was because many of them relied on men for survival. As in many contexts of family frameworks of the refugees in Greek camps, men's role was served as the breadwinner of the family whereas the women must take care of household traditional role which they had to take care of meals and child caring. A report of woman stating that she was hesitant in reporting domestic violence was because she was afraid that she will be let go of economic needs because her husband, which was also the perpetrator of her suffering, had the status of the breadwinner of the family therefore it finds her difficult for her to leave her marriage and take care of her children (Campana 2018).

In addressing the findings by the writer stated above, the analysis of the aforementioned will be stated as follows. Firstly, through bealth, law, and security not responding, the writer sees that when Greek government did not prioritize SGBV as the main concerning issue that happens in the camps, then the settled services to help and aid the refugees will also be limited as well as it was shown by the reports that due to the lack of resources and capacity in which the services in health care must attend to both local natives and the refugee community makes it quite extremely difficult in handling the situation fairly. This also apply to the mentioned aspects in law and security because implementation and availability of 
trusted legal bodies, regulations, and staffs such as interpreters are vital in working to solve the SGBV case altogether. If these were fulfilled accordingly to the numbers needed to the capacity, the writer believes that there would be massive vast improvement of cases being handled and reports regularly created clearly by the right sources available therefore in also giving quick response according to the urgency where violence happen which further helps to prevent and identify forms of SGBV quickly among the refugee camps.

Secondly is in the indicator of religious and cultural justifications in which in this aspect. Since the majority of the refugees came from male-dominated society and Muslim countries therefore the writer pulls the understanding that there are quite wide range of acceptance in the community of refugees that, according to their beliefs, justification through violence as the form of correct discipline which was also due to the dominant culture of male-dominancy in their society in embracing patriarchy values especially from majority Muslim countries of Syria, Afghanistan, and Iraq. With these findings, the writer analyzes that the forms of justification that results towards violence means that there is a negative term and prospects of values and norms implemented in their community as whole where they chose to accept violence as a form of "discipline" which makes it harder for the victims of SGBV to gain their way to freedom in ending their suffering to get away from the violence by speaking out against it.

\section{Interpersonal}

We approach to the indicator of explicit support of $V A W G$ in which this discusses upon the aspects of interpersonal dynamics of involved individuals with refugees, perpetrators, and other actors involved that relates to their surrounding environment. The influences of dynamics between interpersonal relations of each individual derived from the common understanding of general norms and ideas from community therefore there is an influence of discourse shaping the behaviors and attitudes between interpersonal relations. The writer approach to understand how the framework of the weak system in the Greek refugee camps encourage and normalizes violence which ironically also supported by the cultural beliefs of gender norms by the refugee community that unfortunately contributes to the existence of violence occurred in the camps. From sources compiled, it seems that the structure and community in the camps tolerates the behaviors of SGBV because of the fact that there was lack of support in preventing and policing the cause. One source mentioned that violence other than SGBV were also a common occurrence in the Greek camps commanded by the certain population of the refugees as a form of "protests" to voice their distress of living conditions (Karakoulaki 2019). However not every violence was measured properly to voice the distress of the situations, as some violence occurred from fights between ethnics groups also happened in some cases (Limoges 2018). This showcased that the community of refugees in Greek camps are common to face any forms of violence and with such weak approaches in preventing violence, it seems that it enables and tolerates violence throughout the community. Not only that, there were also dismissive behaviors of SGBV even when it was being reported as well. Refugees expressed their concerns of the insecurity of their environment in the camp, however it has been noted that the police, who acts as the local authorities, did little effort to make these preventions possible (Kosmopoulos n.d.).

"Men get drunk and there is no safety. Police will never protect us or intervene. We are also scared that something may happen to our children" - Spoken by 23-year-old Syrian woman in Greek refugee camp (Karakoulaki 2019).

Related statements that echoes similar concerns to the statement above were also reported, showing that there were really little effort of prevention of violence and normalizing the state of violence by the authorities because of the understanding that 
violence is a common occurrences and there is nothing else to do than let it be on its own when in reality it creates the scope of endangerment and heightened insecurity among refugees staying in the camp who merely wishes to feel safe for their lives. This results in bringing stigma to the refugee women who expressed that they have difficulties in reporting SGBV because they were afraid of the social stigma and merely wished to focus on their future plan in moving out of the camp without binding to the complicated bureaucratic burdens (Karakoulaki 2019). Moving on to the second indicator which is internalized acceptance of male superiority/female inferiority in the Greek refugee camps, in which the writer will seek whether there are contributed factors and ideas of how women endanger their safety from internalizing the acceptance of male superiority. In this aspect involves the topic concerning to the perspective upon SGBV through interpersonal relations from individual's act and thoughts. In this area specifically brings to the attention of the mentality it brings to influence the individuals in their relationships as to see the common patters in seeing women becoming victims. This is all due to the mentality of internalizing the ideas and norms placed in the individual of how one should act and think according to the discourse they were built upon. Now this is where it gets problematic because this sort of mentality that internalizes negative traits from general norms build upon the interpersonal relationships, putting women in the lesser positions as they thought of deserving the place because that is what they believe and should follow and accept whatever form of response they take even if it includes violence.

Lastly on to the second indicator of internalized acceptance of male superiority/female inferiority the writer sees that the problematic norms based on the refugees' background, which were majorly male-dominating, creates the situation where women have to accept their situation of defeat in lacking enough skills and power to be able to make choices of their own. Since male roles dominantly overpowers the female roles, seeing that in the Greek camps, men were reported as breadwinners and primary authority in decision-making, brings to the disadvantage of women refugees to be able to carry out their lives with having to be dependent on male figures even though the situation in the Greek camps were in dire state and it has become difficult and stressful for both male and female refugees to be able to find work and income as the asylum framework in Greece were deemed weak by standards. It has brought to the attention of the writer that because women refugees had to internalize the acceptance that they were in inferior roles, especially with the dire situation in Greek camps, they also enable the appearance of violence which furthermore endangers their safety in the first place. And even if it results towards unwanted cases in where they have to accept whatever response shown towards them whether through violence or not, the fact that they had to internalized the negative norms in order to make it out gives worsen impact towards the form of SGBV of enabling it to their space. It is understandable that the situation of the Greek camps was bringing all of the male and female refugees at a disadvantage of security and opportunities, however when it comes to SGBV it seems to be proved difficult to address it due to the fact that they dynamics relations between the women refugees, as victims, and their perpetrators were mostly carried out due to the stressful environment and women being in fear of rejection and shame then turn into silence in result.

\section{Individual}

Starting on with the first indicator of this variable which is men's use of violence against women and girls in which the writer will see if there were any form by the individual aspects in seeing how SGBV formed by the behaviors and attitudes between the involved individuals, which were refugees of both male and female as well as the other actors involved, in seeing how violence influenced by their surroundings in the camps. As far as it is concerned, the 
determinant factors on why violence is used in SGBV is not just because of the formation of structural violence but the morality that influences one individual behavior drives the SGBV form to happen to anybody. It is clear that with the limited source of report in exactly the percentage of types of violence occurred on SGBV against women refugees in Greek camps, there were mentioned several types in the aspects of SGBV format that mentioned in bits and pieces in the available sources which follows were forms of physical and sexual violence for example forced marriage, mistreatment of economic rights, psychological abuse (Thomas, Sian; Darkal, Hoayda; Goodson 2019). It is still unclear from the reports to why men's use of violence against women and girls were justified that it becomes normalized in the Greek camps as a whole especially that it becomes regular occurrence while dismissing the thoughts of women and girls rights however, one thing for sure is that the writer sees that there are forms of behaviors that shaped from individuals of perpetrators in understanding of norms, especially in masculine form, that they justify their actions because on the basis of their understanding with the reasoning from their culture and beliefs.

The last indicator is victims bears costs in which in this aspect, the writer will see the facts of the acknowledgement and response of victims of SGBV and how it impacted their lives afterwards. According to the sources the writer finds, even though SGBV is not a prioritized issue by the Greek government however the government still addresses the case into trying to solve the case along with the NGOs working in the camps. In 2017 it was reported that there was an established protocol in order to help victims in Greek camps to aid with the issue of SGBV where it placed 40 women's counselling centers and 21 state-run shelters for women survivors in which in this shelter it hopes to aid women who went through physical and psychological violence (Costa Riba 2018). However, in reality it was underwhelming limited and there were no available interpreters for all shelters to be able to help the victims making it harder to address the cases happened from them. UN efforts in addressing SGBV were also implemented in working to identify and prevent cases of SGBV happening across the camps in Greek lands, however as it was reported it proved to be quite difficult with the lack of staff and non-fitting strategies to encounter SGBV by the programs as they were mainly focuses on raising awareness and not direct interventions or efforts in decreasing the forms of SGBV (UNCHR 2018).

In seeing how the violence shaped the victims' life, in result there are fear and difficulty from their past experiences in addressing the issue for report. In psychological aspect, victims were being urge against to report SGBV because from fear of social stigma consequences and their distrust towards the justice system which in result silenced them (Thomas, Sian; Darkal, Hoayda; Goodson 2019). In social aspect it seems that it would bring more consequences of repercussions towards the victims instead of the perpetrator as they would be terrified to be rejected by partner, family, and community. For example, in a case women were terrified in reporting SGBV because they didn't want to be taken back to their original country by their husbands or the stigma of victims of SGBV stereotyped as shameful sex workers making them undesirable for the community and dishonor to family (Thomas, Sian; Darkal, Hoayda; Goodson 2019). Meanwhile in cultural and structural aspects, there were influences by the norms of male-dominated power of male and female roles therefore victims will only have to follow and adjust to the practices that were implemented making it extremely difficult for them to voice out their concerns especially when most didn't even realize that they were victims in the first place but felt the impacts of SGBV against them (Thomas, Sian; Darkal, Hoayda; Goodson 2019).

To better understanding the cycle, we approach to the knowledge that SGBV is deeply rooted in communities within societies where they have norms and values that differs to how they apply common gender norms against women and girls. Especially in the case 
where violence can easily break through their social life behind the curtains of 'social norms' then the existence of SGBV easily created through the communities between individuals who deeply rooted with their understanding of said violence in their daily lives. According to UNCHR, there is a common cycle of SGBV apply to refugees through five phases which are; (1) during conflict, prior to flight, (2) during flight, (3) in the country of asylum, (4) during repatriation, (5) during reintegration (UNHCR 2019). The primary reason is because when the conflict happen, the systematic structure constructed by their society are broken which results in women and children facing further risks being faced to SGV when the flee from conflicts and seeking refuge somewhere else (UNHCR 2019).

Table 2: Sexual and Gender--Based Violence During Refugee Cycle

\begin{tabular}{ll}
\hline Phase & Type of Violence \\
\hline $\begin{array}{l}\text { During conflict, } \\
\text { Prior to flight }\end{array}$ & $\begin{array}{l}\text { Abuse by persons in power; sexual bartering of women; sexual assault, } \\
\text { rape, abduction by armed members of parties in conflict, including } \\
\text { security forces; mass rape and forced pregnancies. }\end{array}$ \\
\hline During flight & $\begin{array}{l}\text { Sexual attack by bandits, border guards, pirates; capture for trafficking by } \\
\text { smugglers, slave traders. }\end{array}$ \\
\hline $\begin{array}{l}\text { In the country of } \\
\text { asylum }\end{array}$ & $\begin{array}{l}\text { Sexual attack, coercion, extortion by persons in authority; sexual abuse of } \\
\text { separated children in foster care; domestic violence; sexual assault when } \\
\text { in transit facilities, collecting wood, water, etc.; sex for survival/forced } \\
\text { prostitution; sexual exploitation of persons seeking legal status in asylum } \\
\text { country or access to assistance and resources, resumption of harmful } \\
\text { traditional practices. }\end{array}$ \\
\hline $\begin{array}{l}\text { During } \\
\text { repatriation }\end{array}$ & $\begin{array}{l}\text { Sexual abuse of women and children who have been separated from } \\
\text { their families; sexual abuse by persons in power; sexual attacks, rape by } \\
\text { bandits, border guards, forced/coerced repatriation. }\end{array}$ \\
\hline $\begin{array}{l}\text { During } \\
\text { reintegration }\end{array}$ & $\begin{array}{l}\text { Sexual abuse against returnees as a form of retribution; sexual extortion in } \\
\text { order to regularise legal status, exclusion from decision-making processes; } \\
\text { denial of or obstructed access to resources, right to individual } \\
\text { documentation and right to recover/own property. }\end{array}$ \\
\hline
\end{tabular}

Source: Sexual and Gender-Based Violence against Refugees, Returnees, and Internally Displaced Persons; Guidelines for Prevention and Responses.

In accordance to the explained cycle above, there are factors that involved in creating the issues within SGBV among women and girls, especially in refugee camps. The risks include broken system, poverty, lack of access to education and knowledge on human rights, lack of access to law and trusted authorities, and displacement that are vulnerable towards abuse and exploitation (Danish Refugee Council 2015). All of which are fundamentals to why violence often exists when the system of security is broken down and extremely weak in order to sustain balanced and secure the surrounding environment.

Finally, to address the gathered information stated as above, the writer will analyze the findings and will seek further explanation in analysis of the variable. Based on the findings of the first indicator which is men's use of violence against women and girls in the case of SGBV in Greek camps - the writer analyzes that men's justifying their actions based on their behavior reasoned by gender norms especially on the dominancy of masculine tropes enables the form of violence occurred and targeted towards women refugees which makes it easier for them to force violence upon them. Which also correlates with the fact that the norms of femineity embrace by the women refugees also makes it a disadvantage for the women to fight and voice against the form of SGBV happening towards them. This creates a problematic discourse of SGBV against women refugees in Greek camps because due to the unconditional environment, there were no other support system that strengthened the position of women refugee in order to voice against the violence that happened towards 
them. Whether it came from the related family members, husbands, partners, and staffs of the camps such as authorities with abusing of power by their position - norms and values implemented and acted by the individuals involved in this case were carried out by negative forms of understanding in how one treat another with justified and appropriate behaviors and attitudes but when the slip of negative norms and violence shaped the behaviors of both victims and perpetrators nonetheless enables the existence of violence in the first place.

\section{Recommendation of SGBV Prevention}

First is 'allocating funds and improved Management of financial aspect by working directly between Greek Government and NGO', in which in this recommendation the writer sees that if there were better management and improved dialogues between Greek Government and NGO in directing the flow of funds to the Government so that they can fairly adjust the management in hosting the refugees could lead better result in the camps. Second is 'creating better facilities in healthcare, legal system, and education' in which in these aspects the writer sees that when refugees were provided with better facilities with sufficient workers and capacity then it would lead better environment and lifestyle in the camps for their settlements. Third is 'providing more SGBV-prevention centers that focuses in helping victims with sufficient staff working for it' where it believed to be able to provide enough comfort of shelter for the victims to seek help and from them appropriately with availability of professional staff. The last recommendation is 'progressive programs in identifying and preventing methods to fight SGBV' in which the writer thinks that improved methods that also include deeper context other than society and community level - the levels of interpersonal and individual level is also shared to address equally rather than just praising awareness and sharing knowledge in external spaces but create better program that brings levels of individual and interpersonal discussed and solved too. With this recommendation, the writer hopes the offer will come into the account for future references in identifying and preventing SGBV cases.

\section{CONCLUSION}

The case of SGBV against women refugees in Greek camps in 2015 - 2018 were started by the European migrant crisis that escalated in 2015 in Europe where many asylum seekers try to reach Europe by Greece through using the sea routes in order to land there. Unfortunately, due to the numbers of refugees entered in Greece became the highest point and causing overcrowded camps in Greece refugees' settlements, it becomes quite a difficult situation for Greece to host and attend properly of the refugees' crisis situation where they were not able to handle the mass wave of people staying in the country - which results in many issues arriving in the camps. One of the issues that escalated and caused problems was the case of SGBV in Greek camps. As to why SGBV against refugee women occurs in Greek refugee camps in

2015 - 2018 were analyzed through the Heise model by Lori Michau et.al, where it covers in four levels of societal, community, interpersonal, and individual. Where in each specific levels contributed with variables that showcased how violence influenced each variable continued and affecting by external factors which was imbalance of power/gender inequality which directly affects to the societal level where it further on affects towards community, interpersonal, and individual level. After gathering the information and analyze through the provided model, the writer finds several answers as to why SGBV against women refugees in Greek camps in 2015-2018 happened.

In societal level where it contains the variable of discriminatory laws and policies resulted by the lack of government's efforts in addressing SGBV case in the refugee camps where 
they deprioritize this issue to the side. With the inadequate management of funds that cause the insufficient condition in refugee camps, causing distress of living conditions even from the basic needs to the asylum procedurals. Lastly, there was also lack of will in law and policies in ensuring better legal justice in creating safer and secure protection for refugees staying in the camps and the lack in system to address in specific SGBV law and policy. In community levels contains the variable of inequitable norms and practices where the analysis results the unresponsive judgement and lack of capacity in health, law and security creates pressured situations of authorities handling the SGBV case. There were also justifications carried out through negative norms and values implemented in the community and resulting their acceptance to violence due to their insecurity. The third level is interpersonal which involves the variable of stigma, shame, and silence in which in this case there is a support of VAWG occurred due to the normalization of violence happening in the camps as well as turning to internalized negative norms on male superiority and female superiority. The fourth level which is individual includes the variable of submissive feminity, dominant masculinity in which it addresses on how men's violence against women and girls in the camps resulted by the shape and attitudes that were influenced from the dire environment as well as justification of their actions based on their beliefs. In which it also comes to the end which the victims bear the loss of their rights due to the inaccessible aid and justice available making their places vulnerable.

\section{BIBLIOGRAPHY}

Amnesty International. 2018. Greece: 'T W ant to Decide about My Future' Uprooted Women in Greece Speak Out. Amnesty International. https://www.amnesty.org/download/Documents/EUR2590712018ENGLISH.PDF (December 30, 2019).

Asylum Information Database. "Statistics." Greek Council for Refugees.

Baaz, Maria Eriksson, and Maria Stern. 2018. "Curious Erasures: The Sexual in Wartime Sexual Violence." International Feminist Journal of Politics 20(3): 295-314.

BBC. 2016a. "Migrant Crisis: Migrant Crisis in Europe Explained in Seven Charts." 2016b. "Migrant Crisis: Migration to Europe Explained in Seven Charts." BBC News. https://www.bbc.com/news/world-europe-\%0A34131911\%0A.

BBC News. 2017. "EU to Sue Poland, Hungary, Czechs for Refusing Refugee Quotas." BBC News. https://www.bbc.com/news/world-europe-42270239 (December 27, 2019).

Campana, Fahrinisa. 2018. "Refugee Women in Greek Are Moving Forward. But Many Men around Them Are Not." PRI. https://www.pri.org/stories/2018-08-09/refugeewomen-greece-are-moving- $\% 0 \mathrm{~A} \% 0 \mathrm{~A}$ forward-many-men-around-them-are-not $\% 0 \mathrm{~A}$ (December 30, 2019).

Carina Grun, Gianna. "How the EU's Resettlement Plan Is Failing to Meet Its Goals." $D W$. https://www.dw.com/en/how-the-eus-resettlement-plan-is-failing-to-meet-itsgoal/a-46473093 (December 27, 2019).

Costa Riba, Monica. 2018. "Women Face Daily Dangers in Greek Refugee Camps." Amnesty International. https://www.amnesty.org/en/latest/campaigns/2018/10/women-daily-dangers$\% 0$ Arefugee-camps-greece/\%0A (December 30, 2019).

Council of Europe. 2018. "Report of the Comissioner for Human Rights of the Council of Europe."

Countryeconomy. 2018. "Greece - Population." 
https://countryeconomy.com/demography/population/greece (February 1, 2020).

Danish Refugee Council. 2015. "South Sudan/ Gender Based Violence Research on Sexual Assault." DANISH REFUGEE COUNCIL RESEARCH STUDY.

https://drc.ngo/media/1348919/gbv-report-maban-august-2015.pdf.

Dimitris Skleparis. 2017. “The Greek Response to the Migration Challenge: 2015-2017.” https://www.kas.de/c/document_library/get_file?uuid=9ca070c8-b546-01ac-e85a$\% 0$ Adf93ea2e5297\&groupId=252038.\%0A.

Dockery, Wesley. 2017. “The Balkan Route - Explained, Informants.” Infomigrants.

EIGE. 2016. "Combating Violence against Women- Greece."

ESI. 2015. "The 2015 Refugee Crisis Through Statistics."

https://www.esiweb.org/pdf/ESI -\%0A\%0A Refugee Statistics Compilation - 17 Oct 2015.pdf\%0A (December 27, 2019).

European Comission. 2019. "Managing Migration: EU Financial Support to Greece." Managing Migration: EU Financial Support to Greece. https://ec.europa.eu/home$\% 0$ Aaffairs/sites/homeaffairs/files/what-we-do/policies/european-agenda$\% 0 \mathrm{~A} \% 0$ Amigration/201902_managing-migration-eu-financial-support-togreece_en.pdf.

European Council. "Policies." https://www.consilium.europa.eu/en/policies/migratorypressures/history.

. "Timeline - Response to Migratory Pressures." The European Council.

https://www.consilium.europa.eu/en/policies/migratory-\%0Apressures/historymigratory-pressures/\%0A (December 27, 2019b).

European Institute for Gender Equality. 2013. "Administrative Data Sources on GBV in Greece.” https:// eige.europa.eu/gender-\%0Abased-violence/countries/greece $\% 0 \mathrm{~A}$ (February 5, 2020).

Fernandes, Deepa. 2019. "Mothers and Babies Lack Basic Needs in Greek Refugee Camps.” PRI. https://www.pri.org/stories/2019-07-22/mothers-and-babies-lackbasic-needs-\%0Agreek-refugee-camps\%0A (December 30, 2019).

Frontex. "Migratory Routes." https:// frontex.europa.eu/along-eu-borders/migratoryroutes/western-balkan-\%0Aroute/\%0A (December 26, 2019).

Galtung, Johan. 1969. "Violence, Peace, and Peace Research." Journal of Peace Research 6(3): 167-91.

Greek Council for Refugees. "Victims of Violence." https://www.gcr.gr/en/ourprograms/itemlist/category/60-victims-of-\%0Aviolence\%0A (February 6, 2020).

HIAS. "Definitions: Refugee, Asylum Seeker, IDP, Migrant." http://www.hias.org/sites/default/files/definitions_of_refugee2c_asylum_seeker2c_i dp2c_and_migrant.pdf (December 17, 2019).

Howden, Daniel and Fotiadis, Apostolis. 2019. "Where Did the Money Go? How Greece Fumbled through Refugee Crisis." The Guardian.

ICF. 2018. "Evaluation of the Operation of Regulations (EU) 2016/369 on the Provision of Emergency Support in the Union."

Kalantzakos, Sophia. 2017. "A Paradox in Today's Europe? Greece's Response to the Syrian Refugee Crisis." The Jean Monnet Papers on Political Economy. https://www.uop.gr/images/files/jeanmonnet_15.pdf.

Karakoulaki, Marianna. 2019. “The Invisible Violence of Europe's Refugee Camps.” Aljazeera. https://www.aljazeera.com/indepth/opinion/invisible-violence-europerefugee- camps-191021185959684.html.

Kingsley, Patrick. 2019. "What Caused the Refugee Crisis? You Asked Google - Here's the Answer." The Guardian. 
https://www.theguardian.com/commentisfree/2015/dec/09/what-caused-therefugee-crisis-google (December 17, 2019).

Kosmopoulos, Giorgos. "Refugee Women on Greek Islands in Constant Fear." Amnesty International. https://www.amnestyusa.org/refugee- women-on-greek-islands-inconstant-fear/ (December 30, 2019).

Kuschminder, Katie. 2018. "Deciding Which Road to Take: Insights into How Migrants and Refugees in Greece Plan Onward Movement." https://reliefweb.int/sites/reliefweb.int/files/resources/MigrantDecisionmakingGre ece-Final.pdf.

Leape, Sebastian. 2018. “Greece Has the Means to Help Refugees on Lesbos - but Does It Have the Will?" The Guardian. https://www.theguardian.com/globaldevelopment/2018/sep/13/greece-refugees- lesbos-moria-camp-funding-will (December 30, 2019).

Library of Congress. "Refugee Law and Policy: Greece." : 1-2. https://www.loc.gov/law/help/refugee-\%0Alaw/greece.php\#skip_menu\%0A (December 30, 2019).

Limoges, Barret. 2018. "Clahses at Greek Refugee Camp Leave Hundreds of Civillians Displaced." Syria direct. https://syriadirect.org/news/ethnic-clashes-at-greek-refugeecamp-leave- hundreds-of-civilians-displaced/.

Michau, Lori. 2007. "Approaching Old Problems in New Ways: Community Mobilisation as a Primary Prevention Strategy to Combat Violence against Women." Gender and Development 15(1): 95-109.

- 2015. "Prevention of Violence against Women and Girls: Lessons from Practice." The Lancet 385(9978): 1672-84.

OECD. 2015. "Is This Refugee Crisis Different?"

REC, Programs of EU. 2018. "Gender-Based Violence in Greece Report." http://gendersafer.eu/sites/default/ files/2019-

\%0A\%0A11/Greece.National_Report_0.pdf.\%0A (December 30, 2019).

Taub, Amanda. 2015. "Europe's Refugee Crisis, Explained." VOX.

https://www.vox.com/2015/9/5/9265501/refugee-crisis-europe-syria. (December 8, 2019).

Tempo. 2018. "Yunani Bongkar Jaringan Penyelundup Imigran."

The World Bank. 2019. "Gender-Based Violence (Violence Against Women and Girls)."

Thomas, Sian; Darkal, Hoayda; Goodson, Lisa. 2019. "Monitoring and Reporting Incidents of Sexual and Gender-Based Violence across the Refugee Journey." IRIS: 8-12. https://www.birmingham.ac.uk/Documents/college-social-sciences/socialpolicy/iris/2019/iris- working-papers-29-2019.pdf (December 31, 2019).

THOMAS, CLAIRE. 2011. “Why Don't We Talk about 'Violence' in International Relations?" Review of International Studies 37(4): 1815-36.

UN Women. 2015. "Women Refugees and Migrants." United Nations Women. ."Facts and Figures: Ending VAWG." United Nations Women.

. "Global Database on Violence against Women." https:/ /evaw-globaldatabase.unwomen.org/en/countries/europe/greece (February 5, 2020b).

UNCHR. 2018. "Greek Fact Sheet."

UNHCR. 2016a. "Gender Breakdown of Arrivals to Greece and Italy: Based on Government Data from June 2015 to February 2016." https://reliefweb.int/sites/reliefweb.int/files/resources/20160322-

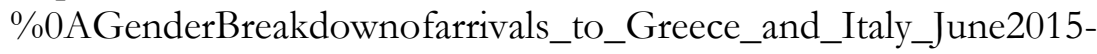
$\% 0 \mathrm{~A} \% 0$ AFebruary2016.pdf\%0A (February 1, 2020). 
2016b. "Refugees \& Migrants Sea Arrivals in Europe: Monthly Data Update."

2017a. "Greece: SGBV - Sector Achievements Dashboard Jan-April 2017."

2017b. "Refugees \& Migrants Arrivals to Europe in 2017."

https://reliefweb.int/report/world/unhcr-refugee-\%0Aand-migrant-arrivals-europe2017-january-december-2017\%0A (February 1, 2020).

. 2018a. "Fact Sheet: Greece."

2018b. "Greece - Accommodation Update." : 1-2.

https://data2.unhcr.org/en/documents/download/67175 (December 30, 2019).

—. 2018c. "Sea Arrivals Dashboard." : ‘. https://reliefweb.int/report/greece/greecesea-arrivals-dashboard-november-\%0A2018\%0A (February 1, 2020).

- 2019. "Sexual and Gender Based Violence (SGBV) Prevention and Response." United Nations High Commissioner for Refugees: 1.

—. "Cash Assistance Program in Greece Information."

. "Operational Portals: Refugee Situation."

https://data2.unhcr.org/en/situations/mediterranean (December 26, 2019b).

Valentza, Christina. 2018. The Greek Reponse to the Refugee Crisis in Eastern Mediterranean (the Period of 2015-2016): An Overview. Istanbul. https://mirekoc.ku.edu.tr/wpcontent/uploads/2019/01/Mirekoc_Report_The-Greek-response-to-the-refugeecrisis-in-Eastern-Mediterranean-web.pdf.

WHO. 2002. World Report on Violence and Health: Summary. Geneva: World Health Organization.

Zafiropoulos, Pavlos. 2016. "Greece Juggles Refugee and Financial Black Holes.” $D W$. https://www.dw.com/en/greece- juggles-refugees-and-financial-black-holes/a19044138 (December 30, 2019). 